\title{
Avaliação da sensibilidade in vitro de Pseudomonas aeruginosa frente ao ácido bórico e ácido acético
}

\section{Evaluation of in vitro susceptibility of Pseudomonas aeruginosa front boric acid and acetic acid}

\author{
Patrícia da Silva Nascente, ${ }^{*}$ Márcia de Oliveira Nobre, ${ }^{* *}$ Tatiana de Ávila Antunes, ${ }^{* \star *}$ José Eurico Vieira Nunes, ${ }^{* \star \star *}$ \\ Mário Carlos Araújo Meireles, ${ }^{* * * * *}$ Luiz Filipe Schuch*****
}

\begin{abstract}
Resumo
Os ácidos bórico e acético são dois anti-sépticos de uso humano e animal que foram avaliados e comparados, no presente trabalho, quanto às suas atividades frente a três isolados de Pseudomonas aeruginosa, provenientes de otite externa canina, através de duas técnicas in vitro de antibiograma, pour plate e ágar difusão. O ácido bórico demonstrou ter maior atividade contra $P$. aeruginosa.
\end{abstract}

Palavras-chave: Pseudomonas aeruginosa, ácido bórico, ácido acético.

\begin{abstract}
Boric acid and acetic acid are two antiseptic of human and animal use, that were appraised and compared, in this work, regarding their activity front three Pseudomonas aeruginosa, from dogs with external otitis, by in vitro two techniques: Pour plate and diffusion agar. Boric acid demonstrated higher ativity against $P$. aeruginosa.
\end{abstract}

Keywords: Pseudomonas aeruginosa, Boric acid, acetic acid.

Otite externa é uma enfermidade comum na clínica de pequenos animais e na maioria das vezes está associada a infecções bacterianas (Grono, 1984; Bornand, 1992; Giorgi, 1996; Nobre et al., 1998) e dentre estas, as otites com envolvimento de Pseudomonas sp são consideradas de difícil tratamento por clínicos e clientes (Rod e Rosychuk, 1994; Foster, 1998; White, 1999). O ácido acético, indicado como anti-séptico em casos de otite externa, vem sendo substituído pelo ácido bórico nas otites humanas, devido ao efeito semelhante com menor poder corrosivo (Eason et al., 1986; Palácio, 2002).

O objetivo deste trabalho foi testar e comparar a atividade in vitro do ácido bórico e do ácido acético frente à bactéria Pseudomonas aeruginosa. Para isso foi estudada a sensibilidade de três isolados dessa bactéria provenientes de casos clínicos de otite externa canina, frente ao ácido bórico a $4 \%$ e ao acético a $1 \%$ (concentrações usuais como antiséptico) utilizando as técnicas de difusão em ágar e pour plate (Bauer et al., 1966; Busta et al., 1984).
Pela técnica de difusão em ágar, foram realizados antibiogramas em duplicata, usando-se anéis de aço inoxidável previamente esterilizados. Os isolados foram suspensos na escala 0,5 MacFarlland e semeados em placas de ágar Müller Hinton com swab estéril, sendo então colocados sobre o ágar dois anéis, afastados $5 \mathrm{~cm}$, cada um contendo $1 \mathrm{ml}$ de um dos ácidos estudados. Para melhor difusão dos ácidos no ágar as placas foram mantidas durante 1 hora a $4^{\circ} \mathrm{C}$ e, em seguida, foram invertidas e incubadas 24 horas a $37^{\circ} \mathrm{C}$. A leitura foi feita com auxilio de régua milimétrica, medindo o halo de inibição do crescimento bacteriano.

Para a técnica de Pour Plate, também realizada em duplicata, foram feitas suspensões dos isolados na escala 1 de MacFarlland que foram distribuídas em alíquotas de $0,2 \mathrm{ml}$, em três tubos que já continham $2,5 \mathrm{ml}$ de ágar $\mathrm{BHI},{ }^{1}$ sendo que dois foram acrescidos com $0,24 \mathrm{ml}$ de um dos ácidos testados e o último com $0,24 \mathrm{ml}$ de salina (controle). Os tubos foram incubados a $37^{\circ} \mathrm{C}$ e após 24 horas foram diluídos em

\footnotetext{
* Universidade Federal do Rio Grande do Sul - Faculdade de Veterinária - Av. Bento Gonçalves, 9090 - Agronomia - Porto Alegre-RS patsn@bol.com.br.

** Universidade Federal do Rio Grande do Sul - Faculdade de Veterinária - monobre@brturbo.com.

*** Universidade Federal de Pelotas - Faculdade de Veterinária - Campus Universitário s/no Caixa Postal, 354 - Pelotas-RS - tadeavila@ibest.com.br.

**** Clínico Veterinário - Pelotas-RS.

***** Universidade Federal de Pelotas - Faculdade de Veterinária - meireles@ufpel.tche.br.

******Universidade Federal de Pelotas - Faculdade de Veterinária - Ifschuc@ufpel.tche.br.

1 Brain-Heart Infusion broth - ACUMEDIA - Asubsidiary of Neogen Corporation.
} 
base $\log 10$ a $10^{-9}$, sendo semeado $0,1 \mathrm{ml}$ de cada diluição, por espalhamento, em placas com ágar sangue e mantidos a $37^{\circ} \mathrm{C}$ por 24 horas, sendo então quantificadas as unidades formadoras de colônias (UFCs).

Na técnica de difusão em ágar foi calculada a média do tamanho dos halos de inibição de crescimento de $P$. aeruginosa formado pelos ácidos acético ou bórico contido nos anéis (Figura 1), obtendo-se respectivamente $146 \mathrm{~mm}$ e $170 \mathrm{~mm}$, demonstrando assim maior eficiência in vitro do ácido bórico em inibir o crescimento de $P$. aeruginosa quando comparado ao ácido acético. Na técnica de Pour Plate, as amostras testadas tanto com salina como com ácido acético apresentaram mais de $30,10^{\circ} \mathrm{UFC} / \mathrm{ml}$, enquanto com ácido bórico o título médio foi acentuadamente reduzido com 7,85.104UFC/ml.

Os resultados demonstram que o ácido bórico foi capaz de inibir in vitro o crescimento de $P$. aeruginosa nas duas técnicas utilizadas, sugerindo-se, com isto, novos estudos avaliando o efeito do ácido bórico na otite externa canina com envolvimento do $P$. aeruginosa.

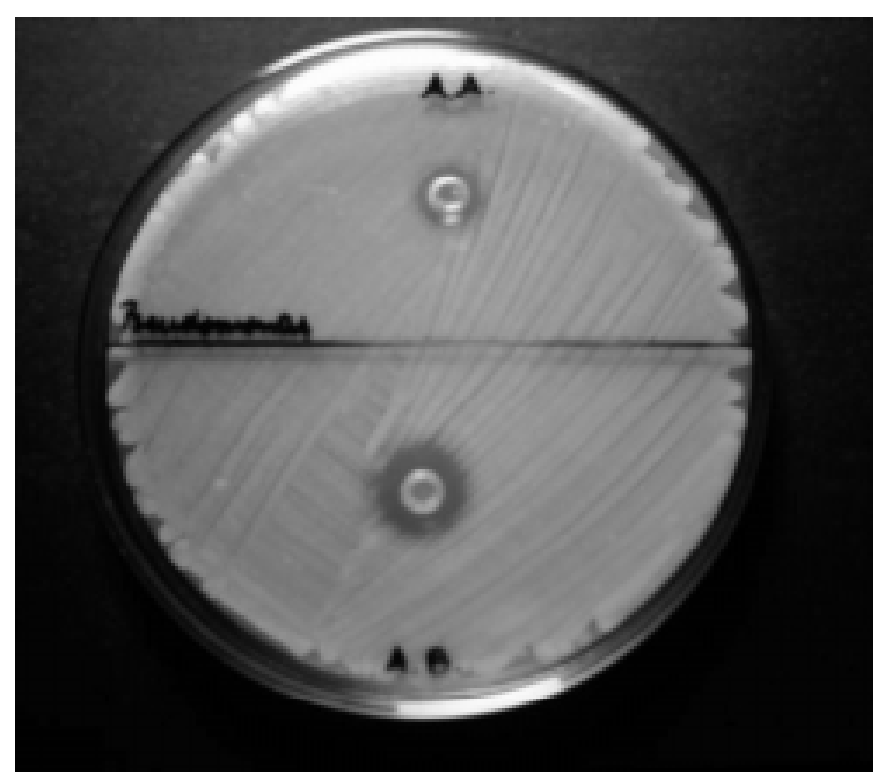

Figura 1: Halos formados pelo ácido acético $(A A)$ e ácido bórico ( $A B$ ) frente a Pseudomonas aeruginosa em placa contendo ágar Müller Hilton.

\section{Referências}

BAUER, A. W.;KIRBY, W. M. M.; SHERRIS, J. C.; TRUCK. Antibiotic suscetibility testing by a standardized single disk method. The American Journal of Clin. Pathol., v. 45, p. 493-496, 1966.

BORNAND, V. Bactériologie et mycologie de l'otite externe du chien. Schweiz. Arch. Tierheilk, v. 134, p. 1-8, 1992.

BUSTA, F. F.; PETERSON, E. H.; ADAMS, D. M.; JOHNSON, M. G. Colony count method. In: SPECK, M.L. ed. - Compendium of methods for the microbiological examination of foods. Waschington, DC American Public Health Association, p. 62-77, 1984.

EASON, R. J.; HARDING, E.; NICHOLSON, D.;PADA, J.; GATHERCOLE, J. Chronic suppurative otitis media in the Solomon Islands: a prospective, microbiological, audimetric and therapeutic survey. N.Z.Med.J., Oct.22; 99 (812), p. 812-815, 1986.

FOSTER, A. P.; DeBOER, D. J. The role of Peseudomonas in canine ear disease. The Compendium, v. 20, n. 8, p. 909-913, 1998.
GIORGI, W.; MARTIN, C. M.; SCHMIDT, E. F. Principais agentes etiológicos da otite externa em cães. Pet. Vet., v. 2, p. 15-17, 1996.

GRONO, L.R. Otite externa. In KIRK RW: Atualização Terapeutica Veterinária. São Paulo, Manole, 1984. 511-516p.

NOBRE, M. O.; MEIRELES, M. C. A.; GASPAR, L. F.; PEREIRA, D.; SCHRAMM, R.; SCHUCH, L. F.; SOUZA, L.; SOUZA, L. Malassezia pachydermatis e outros agentes infecciosos nas otites externas e dermatites em cães. Ciência Rural, v. 28, n. 3, p., 447-452, 1998.

PALACIO, A.; CUETARA M. S.; LOPEZ-SUSO M. J.; AMORE.; GARAU, M. Randomized prospective comparative study: short-term treatment with ciclopiroxolamine (cream and solution) versus boric acid in the treatment of otomycosis. Mycoses. v. 45, n. 8, p. 317-328, 2002.

ROD, A. W.; ROSYCHUK, D. V. M. Managment of otitis externa. Vet. Clin. North Am., v. 24, n. 5, 1994.

WHITE, P. D. Medical management of chronic otitis in dogs. Compendium. v. 21, n. 8, 1999. 